\title{
LA LEY 388 DE 1997 EN COLOMBIA: ALGUNOS PUNTOS DE TENSIÓN EN EL PROCESO DE SU IMPLEMENTACIÓN
}

\author{
María Mercedes Maldonado Copello ${ }^{1}$ \\ Instituto de Estudios Urbanos \\ Universidad Nacional de Colombia
}

Remisión artículo: 26-03-2008

Palabras Clave: Régimen jurídico-urbanístico de la propiedad, políticas de suelo, políticas de vivienda de interés social, derecho urbanístico, ordenamiento territorial.

Resumen: La experiencia colombiana de expedición e implementación de la legislación de ordenamiento territorial y suelo constituye un buen ejemplo sobre el tipo de debates, tensiones y resistencias que en la coyuntura se movilizan en América Latina en este aspecto crucial de la gestión urbana. Varias décadas de esfuerzos para contar con un marco constitucional y legal que ha sentado bases consistentes para la intervención en el mercado del suelo y ha dotado a los gobiernos municipales de herramientas para contar con nuevas fuentes de financiación de la urbanización a partir de la movilización de plusvalías y para apoyar las políticas de vivienda de interés social, las ambientales o las de movilidad entre otras. La legislación ha sido precisada y desarrollada por una amplia e innovadora jurisprudencia, en particular producida por la Corte Constitucional y desde principios de 2000, cuando empezaron a ser aprobados los planes de ordenamiento, atraviesa la etapa más difícil de implementación a nivel municipal, donde se enfrentan problemas que van desde la definición de competencias para adoptar decisiones políticas en este campo, el fuerte arraigo patrimonialista en relación con la propiedad del suelo; hasta la construcción de capacidad institucional pública y privada y la adaptación a un cambio fuerte en las reglas de juego relacionadas con la asignación de las normas de uso y edificabilidad. Tomando en cuenta que la Ley de Desarrollo Territorial llegó el año pasado a sus diez años de vigencia sin mayores modificaciones, el artículo examina tanto los contenidos jurídicos como los puntos de discusión y tensión de este proceso centrado en tres aspectos: 1) las relaciones entre niveles de gobierno o la distribución de competencias, 2) el régimen jurídico-urbanístico de la propiedad a partir de la revisión del significado y alcance de la función social de la propiedad y 3) la articulación entre políticas de suelo y políticas de vivienda de interés social. El artículo aporta elementos para la discusión sobre las mejores condiciones de intervención en el mercado del suelo en las ciudades latinoamericanas dadas sus particulares condiciones en términos de exclusión, desigualdad o inequidad.

\footnotetext{
${ }^{1}$ Persona de contacto: María Mercedes Maldonado, correo electrónico: mmmaldonadoc@unal.edu.co
} 


\section{Introducción}

En un entorno de cuestionamiento, por diversas motivaciones, a la planificación urbana, de preferencia por los (grandes) proyectos urbanos y las intervenciones estratégicas sobre los planes, tildados de inflexibles y pesados, bien sean que provengan de ejercicios burocráticos 0 tecnocráticos, que por igual reciben todo tipo de críticas. En un entorno global de predominio de la regulación de los distintos procesos sociales a través de mecanismos de mercado, el surgimiento y aplicación de legislaciones urbanísticas nacionales, como está ocurriendo en países como Brasil y Colombia no deja de resultar extraño, pero al mismo tiempo estimulante para la discusión sobre las perspectivas de gestión y de políticas urbanas en la región. Dichas legislaciones contemplan la formulación obligatoria de planes urbanísticos (planes directores se les denomina en Brasil y de ordenamiento territorial en Colombia), e intentan dar contenido y alcance concretos a la función social de la propiedad, una categoría propia del discurso político por mucho tiempo confinada a la retórica y a un discurso un tanto difuso, que en América Latina se ha convertido en una categoría jurídica con diversas trayectorias y expresiones; además, están actualizando o renovando los institutos convencionales de regulación del mercado del suelo e incluso se insertan en el discurso o enfoque -también hoy en boga con todas sus ambigüedades- de los derechos.

Para algunos este proceso es visto como una vuelta al pasado, o un nadar contra la corriente, o sería una moda más, quizás pasajera. Los representantes del sector inmobiliario y, sobre todo de la construcción, tienden a manejar posiciones adversas y a movilizar argumentos, ligados a los efectos nocivos sobre los mercados del suelo de este tipo de medidas, la afectación a los derechos de los propietarios o incluso problemas de estabilidad jurídica o de discrecionalidad que supuestamente terminaría afectando uno de las actividades con mayor dinámica en la economía de las ciudades.

En todo caso, y en medio de las críticas, simultáneamente con los procesos, no necesariamente fáciles, de implementación del Estatuto de la Ciudad en Brasil o la Ley 388 en Colombia, en varios países latinoamericanos, distintos actores, públicos o privados, movilizan la necesidad de adoptar leyes de ordenamiento territorial, de mejorar la tributación sobre el suelo o de adoptar políticas de suelo, y, en general, la necesidad de enfrentar el problemático comportamiento de los mercados del suelo en los centros urbanos, donde coexisten situaciones de concentración de la tierra con una veloz movilización de la misma, en procesos formales e informales, así como baja tributación, escasas obligaciones a cargo de los propietarios del suelo, precios del suelo muy altos, sobre todo en relación con el nivel de ingresos de la población, informalidad persistente y una segregación residencial especialmente aguda, así como relaciones patrimonialistas con la tierra².

La legislación colombiana, acompañada de una rica y consistente producción jurisprudencial y de experiencias de aplicación en varias ciudades, aún en proceso de maduración y consolidación, conjuntamente con la brasilera ha marcado la pauta en América Latina de transformación legal, de creación de nuevos ámbitos de discusión de lo jurídico y lo urbano, de replanteamiento del papel que la planeación territorial puede y debe cumplir para asegurar

\footnotetext{
${ }^{2}$ Para un desarrollo de estos argumentos, ver: Smolka Martim O., Mullahy, Laura. Perspectivas urbanas. Temas críticos de políticas de suelo en América Latina. Cambridge, 2007. También consultar los trabajos de Martim Smolka, en http://www.lincolninst.edu/
} 
mejores condiciones de vida y de integración urbana para una población creciente que ha decidido o ha sido empujada a vivir en centros urbanos.

Teniendo en cuenta esta circunstancia y recordando que la Ley 388 se inspira en cierta medida de la legislación española del suelo en su versión de 1992, este artículo examina algunos de los puntos de tensión entre la expedición de un texto legal y el proceso de implementación como pretexto para revisar la manera cómo circulan ideas, categorías e instrumentos trabajados por décadas por el urbanismo y cómo son interpretadas y adaptadas en el contexto de cada país, aportando a la discusión sobre las mejores condiciones de intervención en el mercado del suelo en las ciudades latinoamericanas, con sus particulares condiciones en términos de exclusión, desigualdad y con uno de los peores índices a nivel mundial en materia de distribución del ingreso.

Los aspectos que serán abordados son: 1) las relaciones entre niveles de gobierno o la distribución de competencias, 2) el régimen jurídico-urbanístico de la propiedad a partir de la revisión del significado y alcance de la función social de la propiedad, y 3) la articulación entre políticas de suelo y políticas de vivienda de interés social.

\section{Relaciones entre niveles de gobierno y distribución de competencias referidas al ordenamiento territorial}

Colombia se organiza como una república unitaria, descentralizada y con autonomía de sus entidades territoriales. La Constitución Política reconoce como tales a los departamentos, los municipios y distritos ${ }^{3}$ y los territorios indígenas, y establece la posibilidad de que una Ley Orgánica de Ordenamiento Territorial (LOOT), que aún no ha sido expedida, pueda darles el carácter de entidades territoriales a las regiones y provincias.

La relación entre unidad y autonomía es ambigua desde el mismo texto constitucional, y no ha sido del todo fácil de resolver en el ejercicio concreto de la actividad estatal de cada nivel de gobierno, sobre todo entre las autoridades nacionales y municipales la tensión ha sido permanente. En cualquier caso, las entidades territoriales tienen un relativo margen de libertad para manejar los asuntos a su cargo y detentan derechos reconocidos constitucionalmente: de gobernarse por autoridades propias, ejercer las competencias que les correspondan, administrar los recursos y establecer los tributos necesarios para el cumplimiento de sus funciones y participar en las rentas nacionales, particularmente en los ingresos corrientes de la nación en porcentajes predeterminados y de transferencia automática.

La dirección general de la economía, según la Constitución, está a cargo del Estado. La producción legislativa, evidentemente competencia exclusiva del Congreso de la República, como es propio de un estado unitario, permite ejercer, entre otras la función de intervención económica, precisar los fines, alcances y los límites a la libertad económica. Dicha intervención se extiende a la explotación de los recursos naturales, el uso del suelo, la producción,

\footnotetext{
3 Municipios con régimen especial, como el Distrito Capital de Bogotá y algunas ciudades de la Costa Caribe consideradas como Distritos turísticos. Para efectos urbanísticos la diferencia no tiene mayor relevancia.
} 
distribución, utilización y consumo de los bienes, y en los servicios públicos y privados, y, en general, en la racionalización de la economía.

De acuerdo con la Constitución Política corresponde a los Concejos Municipales "Reglamentar los usos del suelo y, dentro de los límites que fije la ley, vigilar y controlar las actividades relacionadas con la construcción y enajenación de inmuebles destinados a vivienda" (art. 313 numeral 7). La tributación sobre la propiedad inmueble también es competencia exclusiva de los municipios ${ }^{4}$, igualmente dentro de los límites de la Constitución y de la Ley.

La distribución de competencias entre la Nación y las entidades territoriales, de acuerdo con la Constitución (Art. 88) se establecerá a través de una Ley Orgánica de Ordenamiento Territorial, que hasta el momento no ha sido expedida, a pesar de trece o más intentos, porque sus contenidos afectarían intereses electorales regionales y abrirían la puerta a un necesario replanteamiento en la distribución de los recursos fiscales. También porque tendría que avanzar en temas como el reconocimiento de los derechos territoriales de comunidades indígenas y afro-descendientes, de comunidades campesinas y el sistema de áreas protegidas, en especial los parques nacionales naturales, territorios todos que son justamente el escenario del conflicto armado. Aunque muchas leyes, incluso ordinarias, han definido distintas competencias sectoriales, el artículo de la Ley 388 de 1997 que establecía las competencias entre niveles nacional, departamental, metropolitano y municipal fue declarada inconstitucional ${ }^{5}$, por considerar la Corte que este tema era materia exclusiva de la Ley Orgánica de Ordenamiento Territorial.

Aún así, es posible afirmar que las competencias referidas al urbanismo que se trabajan en el presente artículo -ordenamiento físico del territorio, políticas de suelo, construcción y viviendahan sido tradicionalmente municipales, bajo la imprecisa denominación de reglamentación de los usos del suelo, que, como ya se indicó, es competencia de los Concejos Municipales. La Ley 388 de 1997 asume el ordenamiento territorial como una función pública de competencia municipal o de las áreas metropolitanas, y según su artículo 5, "El ordenamiento del territorio municipal y distrital comprende un conjunto de acciones político-administrativas y de planificación física concertadas, emprendidas por los municipios o distritos o áreas metropolitanas ${ }^{6}$ en ejercicio de la función pública que les compete...". El mismo artículo establece que el ordenamiento del territorio se hará tomando en cuenta las relaciones intermunicipales, metropolitanas y regionales, pero varias disposiciones de esta Ley reiteran el carácter municipal de la función pública del urbanismo. Decidir sobre el uso del suelo y sobre su tributación, dentro del marco general definido por la Ley, implica un margen de actuación

\footnotetext{
${ }^{4}$ Con excepción de la contribución de valorización (conocida en muchos países como de mejoras) que puede ser aplicada por otros niveles de gobierno, incluso por entidades como las Corporaciones autónomas regionales, como se denominan las autoridades ambientales y eventualmente la participación en plusvalías (a la cual se hace referencia más adelante), aunque la ley 388 estableció que sería reglamentada exclusivamente por los concejos municipales

${ }^{5}$ Ante una demanda que cuestionaba la intromisión en materia de ordenamiento territorial en las atribuciones de las autoridades indígenas, es decir, en una discusión que no tenía que ver con las competencias propiamente urbanísticas ${ }^{6}$ Según la Ley 128 de 1994, Ley Orgánica de las Áreas Metropolitana. Las Áreas Metropolitanas son entidades administrativas formadas por un conjunto de dos o más municipios integrados alrededor de un municipio núcleo o metrópoli, vinculados entre sí por estrechas relaciones de orden físico, económico y social, que para la programación y coordinación de su desarrollo y para la racional prestación de sus servicios públicos requiere una administración coordinada. Están dotadas de personalidad jurídica de derecho público, autonomía administrativa, patrimonio propio autoridades y régimen especial. Pueden ser creadas por iniciativa de los Alcaldes de los Municipios interesados, la tercera parte de los Concejales de dichos municipios, o el cinco por ciento (5\%) de los ciudadanos que integran el censo electoral totalizado de los mismos municipios.
} 
muy importante de los gobiernos locales (alrededor de 1.100 municipios existen en Colombia, unas 50 ciudades mayores de 100.000 habitantes, y cinco áreas metropolitanas formalmente organizadas) para cumplir con sus obligaciones de orientar el desarrollo y asegurar condiciones de vida adecuadas para la población en términos ambientales y de acceso a las infraestructuras de servicios públicos domiciliarios, vivienda digna y espacio público en general. Para ello, los gobiernos municipales disponen de las siguientes herramientas: un plan de ordenamiento territorial vinculante para actores públicos y privados, la aplicación del impuesto predial $^{7}$ de la contribución de valorización o de la participación en plusvalías y una serie de mecanismos e instrumentos, que serán comentados en el punto siguiente, que permiten movilizar las plusvalías o precios del suelo socialmente creados para producir suelo urbanizado que permita mejorar las condiciones materiales de vida y la integración socio-espacial. La participación de la colectividad en las plusvalías derivadas de la acción urbanística del Estado, al igual que en España, tiene rango constitucional, y hace parte del capítulo de los derechos colectivos y del medio ambiente.

La solución jurídica a la articulación de las decisiones entre el nivel nacional, e incluso instancias regionales, y las autoridades municipales en materia de ordenamiento territorial, habida cuenta que muchos de los procesos espaciales exceden el ámbito políticoadministrativo municipal, fue la de los determinantes de superior jerarquía que deben tener en cuenta los planes de ordenamiento territorial municipal. Dichos determinantes tienen que ver con los distintos aspectos ambientales (desde la gestión de riesgo hasta los sistemas de áreas protegidas), con el patrimonio cultural, incluyendo el histórico, artístico y arquitectónico, con el señalamiento y localización de las infraestructuras relativas a la red vial nacional y regional, puertos y aeropuertos, sistemas de abastecimiento de agua, saneamiento y suministro de energía, así como las directrices de ordenamientos para sus áreas de influencia y los componentes de ordenamiento territorial correspondientes a hechos metropolitanos, cuando exista esta figura.

Cuando inició la aprobación e implementación de los planes de ordenamiento territorial, el ámbito en el cual había relativamente reglas claras era el ambiental, en tanto existía un sistema nacional ambiental ${ }^{8}$ y existían marcos normativos previos que orientaron la definición de los contenidos de los planes. Este marco abrió paso a discusiones y decisiones interesantes en la no siempre fácil relación entre los objetivos ambientales y los de desarrollo urbano. Solo a manera de ejemplo, la discusión entre el alcalde de Bogotá y las autoridades ambientales, asesorada por un grupo de expertos ad-hoc para dirimir el conflicto designado por el Departamento de Planeación Nacional, sobre el uso de 1.600 has localizadas en el norte de Bogotá, en la zona tradicionalmente destinada para usos más rentables, que finalmente quedó calificada como zona de protección ambiental, abrió paso a una reforma legal que convirtió la autorización previa por parte de las corporaciones autónomas regionales de los asuntos ambientales de los planes de ordenamiento, a una simple concertación, que en la práctica resulta ser lo mismo.

Con el paso del tiempo el panorama se ha ido volviendo menos claro: las instancias nacionales han venido produciendo normas de manera un tanto caótica, en respuesta a conflictos

\footnotetext{
${ }^{7}$ O impuesto territorial o a la propiedad inmobiliaria.

${ }^{8}$ Hoy un tanto desdibujado con la fusión del Ministerio de Medio Ambiente en uno solo que tiene a cargo, además, las actuaciones en materia de vivienda y desarrollo urbano.
} 
coyunturales o problemas puntuales e incluso a intereses particulares, de manera que una figura como la de los determinantes de superior jerarquía, dirigida a armonizar, ha derivado en imposiciones del nivel nacional no del todo sustentadas jurídicamente ni necesariamente adecuadas desde el punto de vista técnico, que han producido una creciente incertidumbre relacionada con la vigencia de las normas de usos del suelo y con la primacía de las mismas. Decretos nacionales, y no leyes, han determinado que la ejecución de obras o proyectos de utilidad pública definidos por y a cargo de la Nación, pueden ser ejecutados sin que les puedan ser oponibles las decisiones de los planes de ordenamiento municipal; han intentado, sin mayor claridad, calificar como tributos las disposiciones dirigidas a establecer cargas u obligaciones urbanísticas a cargo de los propietarios de suelo y han llegado al extremo de establecer no solo normas mínimas ${ }^{9}$ para viviendas de interés social, sino remitir directamente a los curadores urbanos $^{10}$ para que apliquen directamente, aún por encima de las disposiciones municipales, estándares que llegan a determinar un lote mínimo en vivienda unifamiliar de $35 \mathrm{~m}^{2}, 70 \mathrm{~m}^{2}$ en vivienda bifamiliar y en agrupación de $120 \mathrm{~m}^{2}$, manteniendo porcentajes fijos de cesiones para áreas verdes y equipamientos ${ }^{11}$, lo que está conduciendo a elevadas densidades y a precarias condiciones de habitabilidad.

Recientemente, la Ley Nacional del Plan de Desarrollo ${ }^{12}$ (que cambia cada cuatro años en tanto recoge el programa de gobierno de cada presidente) ha establecido la posibilidad de desarrollar proyectos nacionales de interés social que podrían llegar a pasar por encima de las normas municipales de usos del suelo.

Más allá de la simple discusión jurídica, está la discusión política. La primera guarda relación, en primer término, con los efectos adversos de esta superposición de normas nacionales emitidas por fuera de los procedimientos legalmente establecidos de revisión de los planes de ordenamiento territorial, y que invaden la órbita de la regulación de los usos del suelo por parte de las autoridades municipales, en una interpretación problemática de la jerarquía normativa que rige los ordenamientos jurídicos occidentales. Los efectos se traducen en incertidumbre jurídica como resultado de la vigencia simultánea de dos disposiciones diferentes 0 contradictorias válidamente expedidas por dos o más autoridades públicas, cuya presunción de legalidad se mantiene para una y otra. En segundo lugar, remite a una discusión sobre el alcance de la actuación municipal: hay una posición proclive a que el control del tema del ordenamiento del territorio esté en buena medida en el nivel nacional, que indica que solo lo que esté previsto de manera específica y detallada en la Ley nacional puede ser aplicado por las autoridades municipales, y otra que plantea que la Ley nacional establece un marco general, en particular en lo que respecta al régimen urbanístico de la propiedad privada del suelo, dentro del cual las autoridades municipales, titulares de la competencia de regulación de los usos del suelo, podrían desarrollar con un margen relativamente amplio de libertad sus actuaciones. Por efecto de la primera posición, por ejemplo, la Ley 388 adolece de un excesivo puntillismo y está recargada de formalidades, que han entorpecido la aplicación de muchos de los instrumentos sin crear necesariamente mayores condiciones de estabilidad jurídica. Los productores de legislación y en general los distintos operadores jurídicos, parecen comprender aún mejor el garantismo respecto a los derechos individuales que de los colectivos.

\footnotetext{
${ }^{9}$ Lo cual sería admisible como parte de las funciones nacionales, pero el problema es que termina equiparando los mínimos a máximos, reduciendo las normas municipales vigentes

${ }^{10}$ Particulares en quienes se ha delegado la función pública de otorgar licencias de urbanismo y construcción

${ }^{11}$ Ver Decreto 2060 de 2004, por el cual se establecen normas mínimas para Vivienda de Interés Social Urbana.

12 Ley 1151 de julio 24 de 2007, por la cual se expide el Plan nacional de desarrollo 2006-2010.
} 
La discusión política remite a las salidas prácticas a la armonización de dos principios constitucionales de la organización política colombiana, que no han alcanzado suficiente claridad: la unidad y la autonomía de las entidades territoriales. Puede ser razonable la preocupación del nivel nacional ante la resistencia o negativa de los alcaldes a que se construya vivienda social en sus territorios o las dificultades crecientes frente a la localización de sistemas de disposición o tratamiento de residuos, entre otros aspectos, pero no parece conveniente que se invada o interfiera en una competencia municipal de larga tradición en nuestros países, como es la regulación de los usos del suelo. No es posible en este artículo detenerse en la justificación elemental para esta consideración: la conveniencia de que sean las comunidades políticas locales, con sus distintas expresiones y fuerzas, las que decidan sobre el ordenamiento de sus territorios.

Por ahora, lo que tendría que ser resuelto a través de mecanismos de coordinación y de complementariedad, se ha venido abordando mediante una estrategia de imposición del nivel nacional sobre el municipal. La tensión está lejos de ser superada, tiene un camino largo por recorrer y no es un asunto banal, habida cuenta de la concreción que ha venido tomando la categoría de la función pública del ordenamiento territorial ${ }^{13}$, donde más allá de la clásica visión de las prerrogativas del poder público, estamos ante un deber de las autoridades municipales de ejercer dicha función, a través de una serie de acciones urbanísticas establecidas en la Ley, con el fin de garantizar derechos colectivos y sociales (como el del medio ambiente sano, el espacio público, la participación en las plusvalías derivadas de la acción urbanística del Estado, la producción de suelo urbanizado de manera ordenada o la vivienda digna). Cuando la tensión entre autoridades de distintos niveles de gobierno es por el cumplimiento de obligaciones o acciones positivas ante la ciudadanía, la discusión adquiere una nueva dimensión.

\section{El régimen jurídico-urbanístico de la propiedad a partir de la revisión del significado y alcance de la función social de la propiedad}

La Ley 9 de 1989, titulada de reforma urbana, es el antecedente inmediato de la Ley 388 y el primer estatuto de planeación y regulación del mercado del suelo en Colombia, expedida luego de cuatro décadas y numerosos proyectos de ley dirigidos a adoptar herramientas para enfrentar los diversos problemas urbanos relacionados con el acceso generalizado a toda la población al suelo urbanizado y las condiciones de financiación de su producción, en ciudades como las colombianas, dominadas por fuertes disparidades en la disponibilidad de suelo urbanizado, por precios del suelo particularmente altos, si se comparan con el nivel de ingresos de la población, y por una importante presencia de las ocupaciones informales.

La Ley 9 contemplaba la formulación de planes de desarrollo municipal para los municipios con más de 100 mil habitantes, inspirados sobre todo en el modelo de la planeación del desarrollo en boga en América Latina desde la década de 1960, que debían incluir planes sectoriales de obras públicas y un reglamento de usos del suelo y cesiones obligatorias, bajo el enfoque de la asignación estática de las normas de usos y edificabilidad. Además contemplaba una serie de instrumentos apenas descritos, tomados de diferentes sistemas urbanísticos: el reajuste de

\footnotetext{
${ }^{13}$ Tomada del sistema urbanístico español.
} 
tierras, inspirado en la experiencia japonesa, el derecho de preferencia a favor de bancos de tierra, según la práctica francesa, la transferencia de derechos de construcción y desarrollo un tanto al estilo norteamericano.

Estos instrumentos se acompañaban de algunos otros de inspiración más local: la extinción del dominio para los terrenos ubicados dentro del perímetro urbano declarados como de desarrollo prioritario que no se urbanizaran o construyeran en un término de dos años; la expropiación sin indemnización ${ }^{14}$ para los propietarios que vendieran, prometieran en venta promovieran o simplemente toleraran ocupaciones informales de sus terrenos, sin ajuste a las normas urbanísticas municipales $^{15}$. Se contemplaba adicionalmente, la disposición de no tener en cuenta en la determinación de la indemnización en caso de expropiación, para evitar un enriquecimiento sin causa, el simple anuncio de proyectos u obras públicas o su ejecución o las compras públicas de suelo realizadas dentro de los cinco años anteriores, o el cambio de normas urbanísticas dentro de los tres años anteriores ${ }^{16} \mathrm{y}$, por último un tributo denominado contribución del desarrollo municipal, que permitía convertir en ingreso fiscal municipal la tercera parte de los incrementos en los precios del suelo producidos por cambios en los usos del suelo o en la destinación de los inmuebles, aumento de densidad o ejecución de obras públicas.

La noción de función social de la propiedad está ligada, en el largo plazo, y en esta etapa de expedición de la Ley 9 de 1989, a la representación de una propiedad sobre la tierra inmóvil vinculada incluso a un discurso sobre rezagos feudales- que debe ingresar a la explotación agrícola o urbana, en el marco de estrategias modernizadoras de construcción del capitalismo. En ocasiones este discurso estuvo ligado a enfoques de corte más social, dirigido a enfrentar la concentración de la tierra, particularmente a nivel rural.

En el terreno urbano, este enfoque se traduce en la reglamentación -usual en los países latinoamericanos- de tarifas más altas del impuesto predial para los lotes de engorde y en figuras como la urbanización o construcción obligatorias, con diversos tipos de sanciones, incluida la pérdida de la propiedad sin compensación alguna. En un segundo momento, el significado de función social de la propiedad se enriquece, en particular con los aportes de la jurisprudencia constitucional y con la discusión ambiental, y se convierte en el conjunto de obligaciones o responsabilidades que se pueden imponer a la propiedad, en particular del suelo. Es decir, que adquiere mayor peso la segunda parte de la fórmula constitucional "la

\footnotetext{
${ }^{14}$ Este mecanismo se conservó en la Ley 388, recortado en detalles y con supresión de los términos de tres y cinco años, pero aún así, se ha convertido en uno de los mecanismos más importantes de control de los precios del suelo y de soporte a los instrumentos de gestión asociada y distribución equitativa de cargas y beneficios, porque permite además, establecer el precio del suelo despojado de expectativas para determinar los aportes de suelo o el cálculo de la participación en plusvalías.

${ }^{15}$ Expropiación que se limitaba al suelo, sin extenderse a las construcciones o mejoras realizadas por los ocupantes, quienes tenían derecho a que les fueran escriturados los terrenos sin realizar pagos adicionales al loteador informal o pirata y con la posibilidad de exigir a este la restitución de las sumas pagadas (para comprender este instrumento hay que tener en cuenta que en Colombia predomina la práctica de la comercialización de lotes por parte de agentes que incluso manejan stocks muy importantes de suelo y por regla general cobran sumas relativamente elevadas por lotes sin ningún tipo de servicio ni equipamiento)

${ }^{16}$ Expropiación que se limitaba al suelo, sin extenderse a las construcciones o mejoras realizadas por los ocupantes, quienes tenían derecho a que les fueran escriturados los terrenos sin realizar pagos adicionales al loteador informal o pirata y con la posibilidad de exigir a este la restitución de las sumas pagadas (para comprender este instrumento hay que tener en cuenta que en Colombia predomina la práctica de la comercialización de lotes por parte de agentes que incluso manejan stocks muy importantes de suelo y por regla general cobran sumas relativamente elevadas por lotes sin ningún tipo de servicio ni equipamiento)
} 
propiedad es una función social que implica obligaciones". A continuación se desarrollan dos temas: el del papel que juega en la delineación de cualquier sistema urbanístico la discusión sobre la movilización de la tierra y, el régimen jurídico urbanístico de la propiedad en la legislación colombiana.

La Ley 9 de 1989 fue demandada casi en su totalidad y declarada constitucional casi en su totalidad por la Corte Suprema de Justicia. Un importante conjunto de sentencias de esta corporación y posteriormente de la Corte Constitucional, creada en 1991, han contribuido en buena medida a construir el derecho urbanístico colombiano, enviando una señal clara de que se ha producido un cambio importante en las reglas de juego. Una de ellas declaró constitucional la extinción del dominio, una de las medidas más extremas que el poder público puede tomar en relación con un propietario de suelo.

Esta decisión judicial y la intención de aplicación de este instrumento por parte de algún gobierno municipal, fue uno de los aspectos que contribuyó a crear el consenso político necesario para la expedición de la Ley 388, asumida como un ajuste de la Ley 9 de 1989 a la Constitución de 1991. Para el sector inmobiliario tenía una gran importancia, aún simbólica, replantear la extinción del dominio, para afirmar las prerrogativas y el margen de libertad del propietario del suelo, respecto a la utilización dada a su propiedad. Es así como fueron aceptados sin mayor oposición otros instrumentos -como la participación en plusvalías-, y se mantuvo la declaratoria de desarrollo prioritario sujeta a venta forzosa en pública subasta, tomando como valor base el precio del suelo en el momento de la declaratoria de desarrollo o construcción prioritaria ${ }^{17}$. Una nueva preocupación acompaña la construcción de consenso sobre la expedición de la Ley 388 y es la búsqueda, antes bien, de mecanismos que agilicen y faciliten la incorporación de tierra para usos urbanos, es decir, una preocupación desarrollista, que vendrá a ser matizada por el conjunto de responsabilidades incorporadas a la propiedad y, en parte, por el surgimiento de la legislación y de las preocupaciones ambientales urbanas.

El régimen jurídico-urbanístico de la propiedad será analizado teniendo en cuenta los principios o regulaciones generales y los instrumentos de planeación y de gestión del suelo.

La principal concepción de la función social de la propiedad ${ }^{18}$, la asume un elemento constitutivo o esencial del derecho de propiedad y no un elemento externo a él, y que dicha función compromete a los propietarios con el deber de solidaridad plasmado en la Constitución y permite conciliar los derechos del propietario con las necesidades colectivas, debidamente fundamentadas. De este principio se desprende que lo que el ordenamiento jurídico colombiano garantiza es el núcleo esencial de la propiedad, entendido como el nivel mínimo de goce y disposición de un bien que permita a su titular obtener utilidad económica en términos de valor de uso y valor de cambio que justifiquen la presencia de un interés privado.

Además, según la Corte Constitucional, “...la configuración legal de la propiedad, como traducción de la función social, puede apuntar indistintamente a la supresión de ciertas facultades, a su ejercicio condicionado o, en ciertos casos, al obligado ejercicio de alguna de

\footnotetext{
${ }^{17}$ Es decir, un mecanismo de recuperación de plusvalías.

${ }^{18}$ Concretada por la jurisprudencia constitucional (derivada de acciones de constitucionalidad y de tutela o amparo, que pueden ser ejercidas por cualquier ciudadano). El lector interesado en conocer en detalle la jurisprudencia y las sentencias organizadas temáticamente, puede consultar a: Pinilla, Juan. Recopilación de la jurisprudencia colombiana: Derecho urbanístico 1991- 2004, en http://www.territorioysuelo.org/legislacion.
} 
ellas." ${ }^{19}$. En la misma sentencia se indica que (...) el usus, en el esquema clásico, facultad esencial derivada de la propiedad, se subordina a la concreta determinación, general y específica de las instancias públicas de planeamiento y desarrollo urbano. Vale la pena insistir entonces, que la función social no remite a simples límites externos impuestos a la propiedad por la acción administrativa del Estado, sino a una redefinición profunda de su naturaleza y contenido, que se concreta a través de planes de ordenamiento territorial municipal, los cuales no estarían limitando o coartando un derecho originalmente absoluto o ilimitado, sino que establecerían hasta dónde y bajo qué condiciones puede llegar el ejercicio de ese derecho en el terreno del urbanismo, es decir, de los procesos de transformación, consolidación, conservación o protección de los distintos territorios que componen un municipio.

Las categorías que constituyen la base de las responsabilidades asignadas a los propietarios de suelo y que concretan el régimen urbanístico de la propiedad son: 1) la clasificación del suelo, 2) la calificación de suelo para vivienda de interés social (VIS) y de áreas críticas para la prevención de desastres, 3) el establecimiento de cargas o responsabilidades a cargo de los propietarios de suelo, como condición previa a la asignación de los derechos o aprovechamientos urbanísticos, 4) la actuación o gestión asociada del suelo urbanizable o de renovación, mediante unidades de actuación urbanística que se ejecutan a través de reajustes de tierras, integración inmobiliaria o cooperación entre partícipes, 5) la participación de la colectividad en las plusvalías derivadas de la acción urbanística del Estado, y 6) la previsión constitucional, de que para la indemnización, en los casos de expropiación, se tendrán en cuenta los intereses del afectado y de la colectividad, y la previsión legal, que establece que la indemnización corresponde al precio comercial del terreno, pero teniendo en cuenta la reglamentación urbanística vigente en el momento de la oferta de compra, es decir, sin incorporar expectativas, así como la destinación económica del terreno y la factibilidad de prestación de servicios públicos domiciliarios, vialidad y transporte, además dispone, que a dicho valor comercial se le descontará el monto correspondiente a la plusvalía o mayor valor generado por el anuncio del proyecto u obra que constituye el motivo de utilidad pública para la adquisición, salvo el caso en que el propietario hubiere pagado la participación en plusvalía o la contribución de valorización, según sea del caso.

No es posible desarrollar un análisis detallado de cada una de ellas, en tanto no es el objetivo de este artículo, pero nos detendremos en algunas de ellas: la clasificación del suelo, mecanismo básico y más importante de configuración de la propiedad, en tanto establece regímenes diferentes de derechos y obligaciones, y procedimientos urbanísticos, según el tipo de procesos de ordenamiento territorial previstos para cada clase de suelo. El suelo se clasifica en urbano, rural y de expansión urbana. El suelo rural puede incluir la categoría de suelo suburbano. En cualquier clase de suelo puede establecerse la categoría de suelo de protección.

El suelo de expansión urbana es el que será habilitado para uso urbano durante la vigencia del plan de ordenamiento, según lo determinen los programas de ejecución ${ }^{20}$ mediando la formulación de un plan parcial y establecida la "factibilidad de extender o ampliar las redes de servicios públicos, la infraestructura vial y la dotación adicional de espacio público, así como los procesos o instrumentos mediante los cuales se garantizará su realización efectiva...". En la categoría de suelo de expansión pueden incluirse áreas de desarrollo concertado, a través de procesos que definan la conveniencia y las condiciones para el desarrollo de las mismas, mediante su adecuación y habilitación urbanística, las cuales estarán a cargo de los propietarios. El desarrollo de estas áreas está condicionado a su adecuación previa. Mientras la conversión de esos suelos en urbanos no se concrete mediante un plan parcial y la

\footnotetext{
${ }^{19}$ Corte Constitucional, Sentencia C-006 de 1993, M.P. Eduardo Cifuentes Muñoz.

${ }^{20}$ A los cuales se hace referencia más adelante.
} 
subsiguiente ejecución de las obras de urbanismo, el suelo continuará teniendo el régimen rural y solo le podrán ser asignados usos agrícolas o forestales, previsión que no solo está contemplada en la Ley sino que ha sido ratificada por varios planes de ordenamiento territorial municipal.

Las obligaciones o responsabilidades urbanísticas que pueden ser impuestas a los propietarios de suelo, según lo concrete cada plan de ordenamiento territorial, son:

1. Las cesiones urbanísticas con destino a vías locales e intermedias de cualquier tipo, equipamientos colectivos o comunitarios, áreas verdes y recreativas y espacio público en general, que se definan en las reglamentaciones municipales. Por lo general los planes de ordenamiento municipal traducen esta obligación en un porcentaje (mínimo del $25 \%$ para áreas verdes y recreativas y equipamientos, más los suelos para vías locales y en algunas ciudades se ha empezado a expresar en metros cuadrados por habitante, sin bajar del mínimo indicado. Un decreto nacional establece como mínimo de espacio público efectivo por habitante que deben asegurar las regulaciones municipales $15 \mathrm{~m}^{2}$ por habitante.

2. Las cesiones o aportes de suelo y la ejecución de obras públicas correspondientes a redes matrices, secundarias y domiciliarias de servicios públicos domiciliarios (particularmente acueducto y alcantarillado) y de vías principales.

Las cargas correspondientes al costo de infraestructura vial principal y redes matrices de servicios públicos se podrán financiar por medio de tarifas de servicios públicos, contribución de valorización, participación en plusvalías y en caso de que no esté previsto ninguno de estos sistemas tributarios, mediante la financiación por parte de los propietarios de suelo a través de la técnica de distribución equitativa de cargas y beneficios, concretados en los planes parciales.

3. La gestión o actuación asociada a través de unidades de actuación urbanística, cuando así lo disponga el respectivo plan de ordenamiento territorial

4. La destinación de un porcentaje del suelo útil de cada proyecto de desarrollo urbano a la producción de vivienda de interés social y,

5. La conservación ambiental o arquitectónica, para la cual existe una reglamentación un tanto confusa y que no ha sido posible aplicar, consistente en el reconocimiento de compensaciones, en el caso de inmuebles particularmente afectados por este tipo de declaratoria en zonas urbanas ya construidas. Dichas compensaciones pueden consistir en reducción en las tarifas de servicios públicos domiciliarios o del impuesto predial; en otros estímulos económicos o en la transferencia de derechos de construcción.

Los instrumentos de planeamiento contemplados en la legislación nacional son el plan de ordenamiento territorial, sujeto a los determinantes de superior jerarquía a los que se hizo referencia en el punto anterior, el programa de ejecución y el plan parcial. El programa de ejecución es un componente del plan de desarrollo económico y social, y de programación de inversiones en el que cada alcalde plasma el programa de gobierno con base en el cual fue elegido, y que define, con carácter obligatorio, las actuaciones previstas en el plan de ordenamiento, que serán ejecutadas durante el período de la correspondiente administración municipal o distrital, señalando las prioridades, la programación de actividades, las entidades responsables y los recursos respectivos. Este documento de planeación deberá incluir varios contenidos importantes: la localización de los terrenos necesarios para atender la demanda de 
vivienda de interés social en el municipio o distrito, la delimitación de las zonas de mejoramiento integral, la indicación de los instrumentos para su ejecución pública o privada, y los inmuebles y terrenos cuyo desarrollo o construcción se consideren prioritarios ${ }^{21}$.

El plan parcial ${ }^{22}$ es el instrumento mediante el cual se desarrollan y complementan las disposiciones de los planes de ordenamiento, para áreas determinadas del suelo urbano, según lo defina cada plan de ordenamiento y para las áreas incluidas en el suelo de expansión urbana, además de las que deban desarrollarse mediante unidades de actuación urbanística, macroproyectos $u$ otras operaciones urbanas especiales. El plan parcial incluye las previsiones relacionadas con las directrices de planeamiento y diseño urbanístico de la respectiva área o proyecto, la definición específica de usos e intensidad de usos y la adopción de los instrumentos de gestión del suelo, captación de plusvalías, reparto de cargas y beneficios, procedimientos de gestión, evaluación financiera y programación de las obras de urbanización.

A continuación se realiza una revisión general a los instrumentos de gestión del suelo ${ }^{23}$, clasificados de la siguiente manera: aquellos relacionados con la producción de suelo urbanizado o reurbanizado y con la movilización de plusvalías para financiar los costos de urbanización; los que sirven de soporte a la adquisición pública de suelo o a la movilización de suelo para los procesos de desarrollo urbano y los instrumentos tributarios de financiación con base en suelo.

En el primer tipo la legislación colombiana contempla básicamente dos alternativas: los bancos de tierra o bancos inmobiliarios, y los reajustes de suelo (en suelo con tratamiento de desarrollo) o integraciones inmobiliarias (en suelo urbano, es decir, en proyectos de redesarrollo o renovación). Como es conocido, los dos apuntan a enfrentar un problema recurrente de los mercados del suelo, cual es la fragmentación de los terrenos producida por los movimientos y transferencias en un régimen en el que domina la propiedad privada, y se basan en la conformación de globos de terrenos lo suficientemente amplios para contar con condiciones adecuadas de diseño y de uso más eficiente del suelo. Los dos involucran movilización de plusvalías, pero se diferencian en que los bancos de tierra se basan en la adquisición pública de suelo para producir los englobes, bien sea a través de compras directas, de expropiación o mediante la utilización del derecho de preferencia o de preémption ${ }^{24}$, bajo la premisa de la adquisición del suelo a precios lo suficientemente bajos o descontaminados de toda expectativa de urbanización, con el fin de financiar los costos de urbanización con la venta del suelo urbanizado y, también, para regular el mercado del suelo gracias a la capacidad de la administración pública de movilizar patrimonios públicos de suelo o una oferta lo suficientemente importante de suelo urbanizado, bien sea para reducir los precios a nivel global o para desarrollar programas de vivienda social y otros de interés para la colectividad.

\footnotetext{
${ }^{21}$ En la actualidad el Decreto 2181 de junio 29 de 2005, reglamenta parcialmente las disposiciones relativas a planes parciales contenidas en la Ley 388 de 1997.

${ }_{22}$ Como base para luego aplicar la venta forzosa en pública subasta.

${ }^{23}$ Se puede ampliar la información en: Maldonado, María Mercedes; Pinilla Juan; Rodríguez, Juan y Valencia, Natalia. Planes parciales, gestión asociada y mecanismos de distribución equitativa de cargas y beneficios en el sistema urbanístico colombiano. Bogotá: Lincoln Institute of Land Policy, 2006. Se puede revisar artículos relacionados con el tema en http://territorioysuelo.org/

${ }^{24}$ Apenas enunciada, de manera escueta, en la Ley 9 de 1989, pero cuya utilización hasta el momento ni siquiera ha sido discutida o prevista por ningún gobierno municipal.
} 
El reajuste de terrenos, por contraste, es una alternativa a la expropiación y, sobre todo, al ingreso de suelos al patrimonio público ${ }^{25} \mathrm{y}$ al mismo tiempo, y sobre todo, un mecanismo de financiación de la urbanización que puede ser adelantando por iniciativa de los particulares, sin intervención pública o con intervención de agencias estatales, por lo general municipales. La premisa básica es que con la venta de una porción de los terrenos urbanizados o reurbanizados o de los aprovechamientos urbanísticos o derechos de construir se financian los costos de urbanización que viabilizan la respectiva operación. Gracias a la utilización complementaria de la técnica del reparto equitativo de cargas y beneficios, en últimas, todo el suelo, independientemente de su destinación final, es pagado a un mismo precio, aquel resultante del reparto, aplicando así el principio de equidad entre los propietarios involucrados y, lo que es más importante, entre éstos y la colectividad. La principal finalidad de los planes parciales, que son a la vez instrumento de planeamiento e instrumento de gestión, es servir de base para la conformación de unidades de actuación urbanística ${ }^{26}$ para su ejecución posterior a través de reajustes de suelo o integración inmobiliaria.

En los primeros años de vigencia de la Ley 388 se ha verificado una tensión en la utilización de estos instrumentos: la creación en 1998 de un banco de tierras en la ciudad de Bogotá, como parte del conjunto de medidas e intervenciones urbanas adoptadas durante el gobierno de Enrique Peñalosa, convirtió este instrumento en protagonista y desde entonces ha sido promovido prioritariamente por el gobierno nacional, en desmedro del reajuste de tierras y la técnica de la distribución equitativa de cargas y beneficios, que a nuestro juicio constituían la esencia de la reforma legal de 1997. Esta promoción se ha hecho incluso desconociendo los diversos problemas de los bancos de tierra: la compra de suelo por parte de las entidades públicas, a pesar de la existencia de normas explícitas dirigidas a controlar los avalúos y a descontar los incrementos de precio ligados a la especulación, termina por lo general en altos precios por dos razones: en nuestra legislación se contempla como obligatoria una etapa previa a la expropiación de enajenación voluntaria dirigida a lograr un acuerdo entre propietario y poder público y, además existe por regla general la expropiación por vía judicial ante los jueces civiles y de manera excepcional, por vía administrativa, cumplidas ciertas condiciones respecto a los motivos de utilidad pública y de urgencia justificada, adelantada directamente por parte de autoridades públicas municipales.

En este marco, ha predominado la idea, equivocada a nuestro modo de ver, de que es mejor pactar precios en la etapa de enajenación voluntaria fácilmente aceptables por el propietario, para evitar las demoras de un proceso judicial y, sobre todo, el riesgo de que los jueces civiles, imbuidos por la concepción civilista de la propiedad, y que por lo general restringen la idea de justicia a la protección del propietario afectado por el poder público, definan indemnizaciones altas. Detrás de esta lógica se esconde una tendencia usual en la utilización de la expropiación, la de pagar precios altos, reconocer simples expectativas y convertir este instrumento, particularmente cuando se trata de adquirir suelo, en una fuente injusta de ganancia a favor del propietario.

\footnotetext{
${ }^{25}$ Obviamente distintos a aquellos destinados a infraestructuras y equipamientos.

${ }^{26}$ La Ley 388, en su artículo 39, define las unidades de actuación urbanística como "...el área conformada por uno o varios inmuebles, explícitamente delimitada en las normas que desarrolla el plan de ordenamiento que debe ser urbanizada o construida como una unidad de planeamiento con el objeto de promover el uso racional del suelo, garantizar el cumplimiento de las normas urbanísticas y facilitar la dotación con cargo a sus propietarios, de la infraestructura para el transporte, los servicios públicos domiciliarios y los equipamientos colectivos mediante reparto equitativo de las cargas y beneficios...".
} 
De otra parte, como los recursos de que disponen los gobiernos municipales habitualmente son escasos, solo pueden adquirir terrenos aislados y de extensión reducida, por lo general en zonas periféricas, con lo cual terminan actuando como un factor de inflación del precio de los terrenos vecinos, no solo por las indemnizaciones comparativamente altas que reconocen sino en razón de las obras de infraestructura que deben realizar para habilitar los suelos para usos urbanos. De esta manera se pierde el factor de control y regulación de los precios del suelo, sin contar, además, con que las entidades públicas asumen todos los riesgos y costos de la titularidad de suelo, y se presentan -como ha ocurrido en el caso de Metrovivienda en Bogotácostos indirectos especialmente altos, factores todos que redundan en que el precio del suelo urbanizado termine siendo más alto que el que logra tramitar directamente un promotor privado, o que haya que reconocer aprovechamientos del suelo excesivamente elevados para facilitar su comercialización, afectando la calidad de vida de los beneficiarios de programas de vivienda de interés social.

Por el contrario, el reajuste ha sido tildado de complicado, demorado y difícil de entender, se enfrenta a problemas de capacidad de gestión en el sector público al tiempo que enormes resistencias entre los propietarios de suelo, en tanto les transfiere de manera explícita buena parte de las obligaciones urbanísticas y los obliga a asociarse con otros propietarios. No se ha contado con suficiente capacitación o apoyo técnico del nivel nacional para su implementación y ha implicado un proceso de aprendizaje más largo de lo conveniente, lo cual ha afectado su alcance y eficacia y redundado en la persistencia de las resistencias.

Los impactos del cambio en las reglas de juego respecto a la apropiación y distribución de las plusvalías, o rentas del desarrollo urbano que la utilización de este instrumento implica, ha llevado a que por ahora las intervenciones de los gobiernos locales han sido tímidas y en muchas ciudades de escaso alcance. Aún así, algunas ciudades como Bogotá, Pereira y Medellín avanzan en la aplicación de la técnica de la distribución equitativa de cargas y beneficios, para contar con alternativas más racionales a la obtención de suelo para fines colectivos y sociales, y con fuentes alternativas de financiación de los costos de urbanización.

\section{El segundo grupo de instrumentos está conformado por:}

1. La expropiación, a la que ya se hizo referencia y de la que se destaca la existencia de la vía judicial o la vía administrativa, y la amplitud, de todas maneras, de los motivos de utilidad pública para recurrir a la vía administrativa, así como la posibilidad de descontar los incrementos en los precios del suelo producidos por el anuncio del proyecto u obra, que constituye el motivo de utilidad pública que justifica la expropiación. Respecto al pago se prevé la posibilidad de pagar en varios contados (entre un $40 \%$ y un $60 \%$ del valor al momento de la adquisición voluntaria y el valor restante en cinco contados anuales sucesivos e iguales, con un interés anual igual al interés bancario vigente en el momento de la adquisición voluntaria), y de realizarlo en efectivo, en títulos valores, derechos de construcción y desarrollo, de participación en el proyecto o permuta, siempre y cuando constituyan efectivamente un medio legal de pago, en documentos fácilmente negociables, que puedan ser convertidos en dinero en cualquier momento e irrevocables unilateralmente ${ }^{27}$.

\footnotetext{
${ }^{27}$ Una sentencia de la Corte Constitucional de 2002 precisó algunos de los alcances de la indemnización, de la cual se pueden derivar, entre otras, las siguientes conclusiones: una interpretación integral de las normas sobre la materia permite establecer que el valor de la indemnización no es equivalente al valor de mercado del bien expropiado y determina que la indemnización se caracteriza por ser un pago reparatorio por los daños causados por una actuación legítima del Estado y que en ningún caso se pueden reconocer pagos adicionales que supondrían un enriquecimiento
} 
Está contemplada también la expropiación a favor de terceros, que puede ser un mecanismo adecuado para apoyar la gestión asociada u otros proyectos de interés colectivo, en el caso de propietarios renuentes, sin tener que comprometer recursos públicos en el pago de las indemnizaciones, que pueden provenir de la venta anticipada de los lotes urbanizados o de derechos de construcción, a través de los fideicomisos que se constituyan para la gestión de los reajustes de suelo o las integraciones inmobiliarias. No obstante, presenta el riesgo de la utilización del poder público en el proceso expropiatorio para desplazar población socialmente vulnerable, sobre todo teniendo en cuenta que es motivo de utilidad pública, incluso para la expropiación por vía administrativa, la ejecución de proyectos de urbanización, redesarrollo y renovación urbana a través de la modalidad de unidades de actuación, mediante los instrumentos de reajuste de tierras, integración inmobiliaria, cooperación o los demás sistemas previstos en la Ley 388 , sin ninguna otra calificación como que sean proyectos destinados a la producción de vivienda social u otros similares de interés colectivo.

2. La declaratoria de desarrollo prioritario sujeta a venta forzosa en pública subasta, a la cual ya se hizo referencia.

El último grupo está conformado por los instrumentos tributarios. Además del impuesto predial, que tiene potencial para recuperar plusvalías y que es utilizado para cumplir objetivos urbanísticos como en el caso de la tarifa más elevada para los lotes de engorde y como mecanismo de compensación de los inmuebles declarados de conservación, existen la contribución de valorización y la participación en plusvalías. La primera permite recuperar el costo de ejecución de obras de infraestructura, más un porcentaje para administración del tributo, entre los propietarios de suelo o de edificaciones localizados en el área de influencia de la obra, sobre la base de que su ejecución produce una valorización de los inmuebles. La segunda se aplica solo al suelo, es decir a los incrementos de precio producidos por los cambios de norma en términos de usos más rentables o mayor aprovechamiento del suelo y también en el caso de ejecución de obras. El límite de cobro es entre el 30 y el 50\% de los incrementos en los precios del suelo, según lo decida el Concejo Municipal en el Acuerdo en que se adopte la aplicación de la participación en el respectivo municipio. En el caso de la ejecución de obras la administración debe decidir cuál de los dos instrumentos aplica. Teniendo en cuenta el límite máximo del 50\% sobre el incremento en los precios, como mecanismo de financiación de obras resulta más eficaz la contribución de valorización que asegura recuperar el costo total de la obra y ofrece mejores condiciones de programación financiera, ya que el hecho generador es la ejecución de la obra y se puede cobrar en un periodo relativamente corto, aún antes de la iniciación de las obras. Por el contrario la participación en plusvalía solo se hace exigible cuando en el momento de la venta del inmueble o de solicitud de una licencia de urbanismo o construcción.

La contribución de valorización es un instrumento con una larga tradición en varias ciudades colombianas y con una utilización relativamente difundida. Sin embargo, presenta algunos

sin justa causa del propietario. Además establece que la expropiación tiene que ser justa, es decir, consultar los intereses del propietario afectado y de la comunidad, como indica la Constitución, y que dichos intereses deben ser ponderados en cada caso concreto, en particular teniendo en cuenta la situación socio-económica del afectado. Como se acaba de indicar, la indemnización por regla general tiene un carácter reparatorio (incluye el daño emergente y el lucro cesante, que debe ser demostrado o justificado), pero en algunos casos puede ser reducido, contemplando los intereses colectivos, y puede tener un carácter simplemente compensatorio o en caso de especial indefensión social del propietario o de vivienda familiar puede asumir una modalidad restitutiva. 
problemas: que se aplica por lo general en áreas urbanas ya construidas, sobre todo para obras de ampliación o mejoramiento vial, mientras que para suelo por desarrollar ha sido poco utilizada, lo que encierra cierta inequidad porque las obras terminan siendo pagadas por los usuarios finales mientras los propietarios de suelo han captado previamente las plusvalías. La otra dificultad se relaciona con su utilización, en algunos casos, para presionar el desplazamiento de población de bajos ingresos de zonas bien localizadas, ante la imposibilidad de pagar el tributo, sin que la ejecución de obras se traduzca para ellos en mayores ingresos. Para corregir en parte este problema, por lo general son exentas del pago de la contribución de valorización las familias de menores ingresos lo que restringe el uso del tributo a las zonas con capacidad de pago y refuerza, de otra manera, la fuerte exclusión que caracteriza las ciudades latinoamericanas.

La principal limitación de la participación en plusvalías radica en una norma -de procedimiento y no sustancial- que solo permite calcular los incrementos del suelo en relación con la norma anterior y no con la situación real del inmueble. Esta disposición, introducida en el trámite en el Congreso, no tuvo en cuenta que en la mayoría de las ciudades en el periodo previo a la Ley 388 , se aplicaron estatutos de usos del suelo basados en la creencia de que el principal papel de la planeación era el estímulo a la actividad inmobiliaria a partir de la asignación de edificabilidades muy altas y sin ninguna contraprestación a cargo del propietario, como supuesto factor de dinamización económica de las ciudades. En muchos casos, la edificabilidad prevista no había sido agotada en el momento de ser expedidos los primeros planes de ordenamiento territorial, razón por la cual el potencial de recaudo de la participación en plusvalías en las zonas urbanas, de ciudades marcadas por fuertes procesos de densificación y de transformación, ha resultado mínimo. Tendrá importancia solamente en las zonas de expansión urbana, lo que de todas maneras no es desdeñable porque además se trata de un tributo con destinación específica, y la mayoría de las destinaciones posibles atiende fines sociales relacionadas con la vivienda social nueva o con programas de mejoramiento.

Por último, planteamos una síntesis de lo que serían las obligaciones a cargo de los gobiernos locales, como expresión de la función pública del ordenamiento territorial que les corresponde:

1. No pueden conceder las normas de uso y edificabilidad de manera gratuita, en particular en los procesos de desarrollo o incorporación de suelos para usos urbanos, y en los de renovación o redesarrollo, porque deben simultáneamente otorgar derechos e imponer obligaciones urbanísticas a los propietarios de los terrenos, y señalar previamente los procedimientos para establecer la factibilidad de extender o ampliar las redes de servicios públicos, la infraestructura vial y la dotación adicional de espacio público, así como los procesos o instrumentos mediante los cuales se garantizará su realización efectiva y la equitativa distribución de cargas y beneficios derivados de la correspondiente actuación.

2. Deben posibilitar a todos los habitantes el acceso a las vías públicas, las infraestructuras de transporte y demás espacios públicos y su destinación al uso común y hacer efectivos los derechos constitucionales a la vivienda y los servicios públicos domiciliarios.

3. Deben asegurar la oferta de suelo para vivienda de interés social en proporción adecuada a la composición social de la población.

4. Deben impedir que haya en su municipio población que habite en zonas de riesgo ${ }^{28}$.

\footnotetext{
${ }^{28}$ Situación que desafortunadamente es usual en las ciudades colombianas, como una de las expresiones extremas de la informalidad
} 
5. Debe aplicar los tributos sobre el suelo de que dispone, para hacer efectivo el derecho de la colectividad de participar en las plusvalías derivadas de la acción urbanística del estado.

6. Debe revisar, y si es del caso, impugnar los avalúos que se realicen para la aplicación de los distintos instrumentos de gestión del suelo.

Esta concepción de la función pública del ordenamiento del territorio, como ya se indicó, es un aspecto muy importante, ante la creciente interferencia del nivel nacional, porque no se estarían limitando o matizando con ese tipo de intrusiones simples prerrogativas del poder público, sino el cumplimiento de ciertos deberes ante la ciudadanía, amparados por supuesto de manera general en la Ley y, en muchos, casos, coartados o desdibujados por decretos nacionales.

La relación de estas regulaciones con las políticas de vivienda de interés social, que se tratarán en el punto siguiente, muestra que aún falta mucho por hacer para lograr que se ejerzan los deberes, atribuciones y herramientas que la Constitución y la Ley 388 ponen a disposición y exigen a los gobiernos locales.

\section{Políticas de suelo y vivienda de interés social}

La relación entre políticas de suelo y políticas de vivienda de interés social, constituyen una de las principales paradojas que ha enfrentado la implementación de la Ley 388. Una de las preocupaciones centrales y reiteradas de los actores que participaron en el largo proceso de formulación de las leyes 9 de 1989 y 388 de 1997, fue la búsqueda de alternativas de solución a los problemas de acceso a la vivienda para los sectores más pobres de la población, alternativas centradas en la solución a los problemas de pobreza e inequidad, ligados a los mecanismos existentes de apropiación de la tierra y distribución de las rentas derivadas del desarrollo urbano, tal como está planteado en algunos de los proyectos de ley. El rechazo durante décadas a la aprobación de una ley de reforma urbana coincide con el periodo en el cual se verifica un acelerado proceso de urbanización, marcado por una fuerte participación de las ocupaciones informales.

Justo en el momento de expedición de la Ley 9 de 1989 y de la Constitución de 1991, que incluyen las herramientas de intervención en el mercado de la tierra a disposición de los gobiernos municipales, que se acaban de describir, se produjo una profunda reorientación de las políticas de vivienda social, que, esencialmente, pasaron de actuaciones del lado de la oferta de vivienda y crédito por parte de entidades nacionales, en algunos casos complementados con entidades municipales o departamentales, a la adopción, recortada, del sistema de subsidios directos a la demanda cuya aplicación se inició en Chile. La vivienda para los sectores populares fue insertada en una política de incentivación económica al sector de la construcción, en lugar de una política social.

Este cambio produjo un fuerte desmonte institucional de la actuación estatal en los diferentes factores involucrados en la producción de vivienda (crédito, tecnologías, materiales, gestión del suelo, entre otras), de las organizaciones y programas comunitarios o cooperativos de autogestión, y la intervención estatal se redujo al manejo de un fondo nacional que otorga subsidios en dinero, que cubren entre un 10 y un 30\% del precio de las viviendas y en el mejor 
de los casos el $50 \%$, en los casos de población en condiciones extremas de vulnerabilidad ${ }^{29}$. El resto del precio, debe ser aportado por las familias a través de un ahorro programado y de un crédito bancario, que es muy difícil de obtener para las personas de menores ingresos 0 vinculadas informalmente al trabajo.

De otra parte, se pretendió que un aporte individual en dinero en la proporción indicada, iba a servir de estímulo suficiente para que el sector privado atendiera la producción de vivienda a precios accesibles para un porcentaje importante de la población, que enfrenta problemas crecientes de pobreza, altos niveles de desempleo, precarización del empleo cuando no vinculación estructural al trabajo de manera informal.

Las políticas de suelo fueron unas de las grandes ausentes del nuevo enfoque de las políticas de vivienda. Durante años el nivel nacional prestó mínima atención a la necesaria coordinación y colaboración que tendría que existir entre los niveles de gobierno, para actuar en lo que actualmente se reconoce como uno de los principales cuellos de botella de las políticas de vivienda de interés social, la disponibilidad de suelo urbanizado y bien localizado adecuado para la construcción de vivienda de bajo precio. No solo no se apoyó la implementación de políticas de suelo enfocadas a la producción de vivienda de interés social, sino que la timidez y lentitud en la adopción de los instrumentos de la Ley 388, así como la inercia de las regulaciones de los usos del suelo, basados en la valorización del suelo de propiedad privada sin contraprestación a cargo de los propietarios de suelo, que prevén grandes zonas para los usos rentables, mientras las calificadas para vivienda social no guardan la más mínima relación con la composición socio-económica de la población, ha redundado en la presencia de precios altos del suelo a nivel de las ciudades como un todo y en fuertes procesos de especulación.

Como si esto fuera poco, el objetivo de incentivo al sector de la construcción, además de exenciones tributarias y de los subsidios directos a la demanda, se ha acompañado de políticas de suelo basadas en el incremento en los aprovechamientos del suelo, bajo la creencia equivocada de que de esa manera se estimula la producción de vivienda social. Como ya se señaló, se ha llegado al extremo de una reglamentación nacional vía Decreto, que intenta sobreponerse a las decisiones municipales, determinando unas áreas de los terrenos destinados a vivienda social de las más pequeñas de América Latina ${ }^{30}$. El efecto ha sido el contrario al planteado como justificación para expedir esta norma: incremento en los precios del suelo, de manera similar a lo que ocurre con los subsidios directos a la demanda, al habilitar 0 mejorar la capacidad de pago de las familias más pobres.

Para apoyar la oferta de suelo urbanizado para vivienda de interés social la Ley 388 , en su artículo 92, contempla una disposición que refleja la preocupación por servir de soporte a este tipo de políticas y que establece que las autoridades municipales determinarán sus necesidades en materia de interés social y de acuerdo con las mismas definirán los objetivos de mediano plazo, las estrategias e instrumentos para la ejecución de programas tendientes a la solución del déficit correspondiente. En todo caso, continúa esta norma, al incorporar suelo de expansión urbana, los planes de ordenamiento y los instrumentos que los desarrollen

\footnotetext{
${ }^{29}$ No solo son reducidos los montos individuales asignados sino los montos globales, de manera que el impacto frente a la informalidad ha sido reducido.

${ }^{30}$ En particular el lote de $120 \mathrm{~m}^{2}$ para vivienda multifamiliar, donde en un sistema de agrupación se construyen hasta siete pequeñas casas, que pueden llegar cada una a una altura de 3 pisos, pero que reducen de manera dramática los espacios privados disponibles, en contravía con la noción de vivienda digna y además en medio de altas densidades.
} 
determinarán porcentajes del nuevo suelo que deberán destinarse al desarrollo de programas de vivienda de interés social. Igual previsión habrán de contener los planes parciales para programas de renovación urbana. Lo anterior, sin perjuicio de que este tipo de programas se localicen en otras zonas de la ciudad, de acuerdo con las normas generales sobre usos del suelo. Los planes parciales correspondientes determinarán la forma de definir las localizaciones de los terrenos tendientes al cumplimiento de los porcentajes expresados.

En la última Ley nacional del plan de desarrollo se estableció como de obligatoria y directa aplicación, aún sin estar previsto en los planes municipales, la destinación de por lo menos un $25 \%$ del suelo útil de cualquier proyecto de desarrollo a la producción de vivienda de interés socia $^{31}$, o el $15 \%$ a vivienda de interés prioritaria ${ }^{32}$. Las autoridades municipales pueden incrementar esos porcentajes y precisar la destinación y, de no hacerlo, será el propietario del suelo el que decida el tipo -o precio- de la vivienda que se construye dentro de las alternativas propuestas.

La aplicación de esta disposición, aunque aparece insuficiente ante el porcentaje de población urbana de bajos ingresos y empleo precario, podría ser el inicio de la solución al problema de la debilidad de las políticas de suelo en este terreno, que, no obstante, está acompañado de vacilaciones y ambigüedades, como la que permite el traslado de la obligación a otras zonas de la ciudad, manteniendo los agudos patrones de segregación socio-espacial, o problemas en los criterios de cálculo de las equivalencias entre las zonas originales y aquellas a donde se puede trasladar la obligación, debilidades que pueden ser objeto de ajuste y mejoramiento. Esta herramienta y el anuncio reciente de algunas ciudades de iniciar la utilización de la declaratoria de desarrollo prioritario, para posterior subasta del suelo calificado para vivienda de interés social, abriría la puerta a un avance realmente significativo en la aplicación de la Ley 388 al que habrá que hacer seguimiento y evaluación en los próximos años, así como a la utilización de los reajustes de terrenos con distribución equitativa de cargas y beneficios que permitan superar las dificultades y sobrecostos de los bancos de tierra.

\section{Comentarios finales}

Hay dos aspectos por resaltar del proceso de implementación de la Ley 388 de 1997: primero, que llegar a diez años sin mayores modificaciones, en un país donde incluso la temporalidad de la Constitución se acerca o se ha vuelto incluso menor que la de las políticas públicas, es un logro importante que refleja cierta madurez de los actores públicos involucrados en este campo de la gestión urbana y una mediación hasta ahora adecuada ante los intereses privados. Esta circunstancia ha proporcionado un espacio de estabilidad para el proceso de comprensión, aprendizaje y aplicación de los instrumentos. El segundo aspecto por destacar, es simple y llanamente, que se está aplicando, lo cual también es importante en América Latina donde es habitual que la ley no se aplique o que se obedezca pero no se cumpla, según el conocido dicho popular. Como se ha indicado, la aplicación de los instrumentos de gestión del suelo no se ha generalizado en todos las ciudades, el proceso ha sido más lento de lo deseable y, sobre todo no se ha utilizado todo el potencial que la ley permite, porque tienden a predominar ciertas inercias, falta de visión o de compromiso político con el tema de muchos alcaldes, así como un desbalance en el garantismo, más del lado del derecho de propiedad que de los derechos e

\footnotetext{
${ }^{31}$ Que tiene un precio entre US 16.000 y US 31.000. definido legalmente.

${ }^{32}$ Con precio de hasta US 16.000 .
} 
intereses colectivos y sociales. Aún así, el proceso de implementación está en marcha y tiene posibilidades.

Una expresión de la indecisión o falta de compromiso de muchos de los gobiernos locales, ahondada por las señales ambiguas del nivel nacional, que en los últimos años ha jugado más en el sentido de poner frenos y límites que en el de estimular la aplicación, es el peso que juega la profusa jurisprudencia, derivada de acciones ciudadanas de inconstitucionalidad, de tutela o amparo, de legalidad o acciones populares o de cumplimiento. Ante la vacilación del poder público nacional y local los ciudadanos han jugado un papel importante movilizando el poder judicial en la búsqueda de efectividad de una legislación por largos años construida con el fin de reorientar la lógica de actuación de un mercado caracterizado por la exclusión y la inequidad. En este momento estamos en la revisión judicial de los primeros instrumentos municipales de gestión del suelo, a la espera de que se reafirmen los principios e interpretaciones a favor de interés colectivo hasta ahora establecidos por los tribunales. Esta circunstancia se ha convertido, por ahora, en un factor de apoyo a la implementación.

De todas maneras, hay razones para ser optimistas: en los ámbitos de la administración pública, académicos y ciudadanos el debate se mantiene vigente, se ha cualificado, contribuyendo también a mejorar las condiciones que hagan más fluida el diseño y la aplicación de los instrumentos. Es de esperar también una segunda etapa de acciones ciudadanas dirigidas a presionar la aplicación local de los instrumentos con mayor impacto social. En aspectos como los criterios para la elaboración de avalúos, la utilización de tributos con base en suelo (como la contribución de valorización o la participación en plusvalías o el fortalecimiento de las formaciones catastrales y el impuesto predial) los avances son innegables, como lo muestran algunos de los artículos incluidos en esta publicación. Incluso en relación con los planes parciales parece atemperarse la importancia de su aplicación, a pesar de que han estado en el ojo del huracán porque significaron quizás el cambio más fuerte en las reglas de juego. De la asignación gratuita e incondicionada de las normas de uso y edificabilidad a la asignación condicionada a la financiación de las obras de infraestructuras viales y de servicios públicos y de espacio público en general, del desarrollo predio a predio a la gestión asociada que permite un uso más racional del suelo.

Los primeros planes de ordenamiento territorial fueron aprobados hacia el año 2000, y en ellos se dio más fuerza al planeamiento que a la gestión del suelo, en 2003 se inició la etapa de revisión ordinaria en varias ciudades y ahora nos aproximamos a la revisión general de los planes, etapas en las que cada vez cobran más presencia las políticas de suelo, al igual que en la formulación de los planes cuatrienales de desarrollo económico y social.

En un taller realizado en mayo de $2007^{33}$, con funcionarios de planeación municipal de 19 municipios de diferente talla y localización regional, se elaboró un documento que señala que existe un amplio consenso entre los participantes acerca del cambio positivo que significó pasar del planeamiento puntual, reducido a los Códigos de Urbanismo, como ocurría antes de la Ley 388, al ordenamiento basado en una visión del territorio en un marco al menos de mediano plazo, con obligaciones de los gobiernos municipales ante la ciudadanía, que permiten superar una actuación que apenas seguía el vaivén de los intereses que se manifestaban bien sobre la administración, bien sobre los concejos municipales. La norma se ha convertido apenas en un componente dentro de un conjunto más amplio de instrumentos dentro de un marco regulador más estable que obliga a los distintos intereses a manifestarse simultáneamente y pone directamente en la mesa de discusión la necesidad de un balance general de propuestas e intereses.

\footnotetext{
${ }^{33}$ Como parte de las actividades preparatorias del Seminario 10 años de la ley 388 de 1997: sus aportes al ordenamiento urbano y a la consolidación de políticas de suelo. Salón Elíptico del Congreso de la República convocado por el Congreso de la República y la Universidad Nacional de Colombia con el apoyo del Lincoln Institute of Land Policy, Bogotá, Mayo 24 y 25 de 2007, se puede consultar el documento en http://territorioysuelo.org/eventos
} 
Evidentemente existen problemas de capacidad institucional, tanto en las entidades del nivel nacional como del municipal. En muchas ciudades la aplicación de la Ley 388 llegó en un momento de reducción presupuestal y recortes de personal, y también es un problema la presencia muy reducida de funcionarios de carrera administrativa, de manera que con cada cambio de gobierno (hasta 2003 cada 3 años, actualmente 4) se inicia prácticamente de cero por los cambios de los funcionarios y asesores. Hizo falta diseñar procesos adecuados de transición, así como de información y formación. Como se señaló, la ley es excesivamente puntillista y cargada de procedimientos, y presenta en varios ítems importantes problemas de técnica jurídica en su redacción, lo cual opera como un obstáculo para su comprensión, encarece y enrarece ciertos procedimientos y abona el terreno para conflictos, judiciales o no, basados en simples consideraciones formales.

Como se señaló en el taller antes mencionado, los problemas de fortaleza técnica y capacidad de respuesta ante el cambio exigido por la ley en las prácticas de planeamiento y de las políticas de suelo no se reducen a los funcionarios públicos: los organismos de control, los curadores urbanos, las autoridades ambientales, los jueces municipales encargados de definir los precios indemnizatorios en los casos de expropiación o conflictos puntuales y también los agentes privados han enfrentado dificultades para entender el nuevo marco jurídico y sujetarse a él.

La falta de acompañamiento con procesos de formación y de capacitación y la debilidad de los equipos municipales han implicado que en que en muchos casos la elaboración de los proyectos de planes quedara en manos de consultores que no necesariamente contaban con suficiente capacidad técnica y que tendieron a uniformizar y repetir recetas y formatos.

Los participantes en el taller en cuestión concluyeron que los actores políticos y gubernamentales locales "...comienzan a entender y aplicar la Ley y los agentes privados se van acomodando a ella con diferentes grados de resistencia. La implementación ha sido un proceso complejo de mucho aprendizaje, en el que se va reconociendo una amplia gama de oportunidades para el ordenamiento territorial de los municipios, enfrentada a inercias, bajo conocimiento de la ley y conflictos propios de los dilemas entre los actores interesados".

Los instrumentos con los que contaba el municipio frente a los actores privados eran escasos, razón por la cual las herramientas que ofrece la ley son fundamentales para fortalecer la gestión pública municipal. Creer en la propiedad, iniciativa y gestión privadas, no excluye la necesidad de tener en cuenta el papel que juega el Estado y la necesidad de regular e intervenir el mercado del suelo.

En el terreno de las discusiones conceptuales, en la coyuntura se verifica un debate que ha estado presente en muchos de los países y ciudades que han adoptado legislaciones de ordenamiento territorial y suelo y las han desarrollado a través políticas, actuaciones e instrumentos: la tendencia a definir como tributario cualquier instrumento que incluya la condicionalidad en los usos e intensidad de usos del suelo, que las someta al cumplimiento de obligaciones urbanísticas, o que establezca diversas posibilidades de pago por el derecho de construir, en procesos de gestión asociada o no o incluso su comercialización representada en valores, a través de bolsa o en mercados de otro tipo. Este debate encierra una resistencia a aceptar el profundo ajuste conceptual que han sufrido interpretaciones manipuladas de la propiedad civilista, que supuestamente integraría todos los atributos de manera unitaria y absoluta en cabeza del propietario del suelo. El usus (del suelo), como lo indica una de las sentencias de la Corte Constitucional colombiana que se ha comentado e incluso buena parte de la doctrina en una perspectiva de largo plazo, está sujeto a la determinación que de él se haga en las instancias públicas de planeamiento o, en otras palabras, hace parte del ámbito de la comunidad y no es un atributo exclusivo del propietario. Cuando los planes definen el 
alcance y el contenido del derecho de propiedad, adquiere particular importancia que los procesos de ordenamiento territorial trasciendan y se difundan en el conocimiento y debate ciudadano, sean conocidos y controlados por un número amplio de actores urbanos.

También encierra la resistencia a reconocer la diversificación y actualización de los enfoques e instrumentos de la hacienda pública y de la naturaleza y alcance de los recursos públicos o ingresos fiscales, como expresión de procesos de modernización y de evolución de la gestión pública. Los agentes inmobiliarios de nuestros países se insertan sin problema en los circuitos globales de inversión, mientras que en sus espacios locales continúan atados a viejas prácticas patrimonialistas y al manejo inmediatista y especulativo de sus intereses.

Esta discusión guarda además relación con aquella, ya clásica en el urbanismo, sobre los criterios y mejores alternativas de financiación de la urbanización, sobre las posibilidades de vinculación de los propietarios de suelo, versus alternativas de perecuación de costos entre el conjunto de contribuyentes de la ciudad o sobre el vinculo lógico y razonable que debe existir entre cada operación urbana y las infraestructuras y equipamientos que se financian con cargo a aquella que remite al de las relaciones entre el aprovechamiento del suelo y los soportes urbanos necesarios para generar ciudades en las que la calidad de vida constituya una de las bases de la integración social y se superen rupturas profundas en el vínculo social como aquellas derivadas de la negación para un porcentaje importante de la población del acceso a los elementos materiales elementales que definen la ciudad y la ciudadanía, como los servicios públicos en red, la accesibilidad y movilidad o los equipamientos sociales, sin contar con el acceso a la vivienda digna.

La experiencia colombiana enfrenta varios espacios de tensión pero también de posibilidades de construcción, que se espera en un futuro no muy lejano se resuelva a favor de los intereses colectivos, de formas de hacer ciudad con menos exclusión y mayor redistribución. Recogiendo las tensiones que se ha intentado describir y explicar en este artículo: un balance adecuado entre las atribuciones del nivel nacional y las atribuciones de los gobiernos municipales, para avanzar hacía una mayor colaboración en lugar de interferencias inconvenientes y juegos de poder; un balance eficaz entre las responsabilidades de los propietarios del suelo y las de los gobiernos locales como titulares de la función pública del urbanismo, de cara al conjunto de ciudadanos que habitan y disfrutan cada ciudad, y mucha claridad y firmeza para que los instrumentos construidos en un largo proceso político y jurídico contribuyan, entre otros objetivos, a mejorar el acceso al suelo urbanizado y a la vivienda de los más pobres, rompiendo con los múltiples círculos viciosos de la informalidad. 


\section{Bibliografía.}

Maldonado, María Mercedes; Pinilla, Juan; Rodríguez, Juan; Valencia, Natalia. Planes parciales, gestión asociada y mecanismos de distribución equitativa de cargas y beneficios en el sistema urbanístico colombiano. Bogotá: Lincoln Institute of Land Policy, 2006

Smolka Martim O., Mullahy, Laura. Perspectivas urbanas. Temas críticos de políticas de suelo en América Latina. Cambridge, 2007.

Trabajos técnicos y de investigación consultados

Maldonado, María Mercedes, Pinilla, Juan Felipe. La jurisprudencia de las altas cortes colombianas en materia urbanística como soporte para las políticas municipales de suelo. Documento elaborado como resultado del trabajo de investigación Construcción de las Líneas jurisprudenciales de las altas cortes colombianas en Derecho Urbanístico colombiano, Lincoln Institute of Land Policy, Bogotá, mayo de 2007, no publicado.

Recursos de internet consultados

Pinilla, Juan Felipe. Recopilación de la jurisprudencia colombiana: Derecho urbanístico 19912004, en http://www.territorioysuelo.org/legislacion

Legislación y jurisprudencia colombiana consultada

República de Colombia, Congreso de la República. Ley 9 de enero 11 de 1989, por la cual se dictan normas sobre planes de desarrollo municipal, compraventa y expropiación de bienes y se dictan otras disposiciones.

República de Colombia, Asamblea Nacional Constituyente. Constitución Política de Colombia de 1991.

Corte Constitucional, Sentencia C-006 de 1993, Magistrado ponente Eduardo Cifuentes Muñoz.

República de Colombia, Congreso de la República. Ley 128 de 23 de febrero de 1994, por la cual se expide la ley orgánica de las Aéreas Metropolitanas.

República de Colombia, Congreso de la República. Ley 388 de 18 de julio de 1997, por la cual se modifica la Ley 9 de 1989 y se dictan otras disposiciones.

Corte Constitucional, Sentencia C-1074 de 2002, Magistrado ponente Manuel José Cepeda. 
República de Colombia, Decreto 2201 de agosto 5 de 2003, por el cual se reglamenta el artículo 10 de la Ley 388 de 1997.

República de Colombia, Ministerio de ambiente, vivienda y desarrollo territorial, Decreto 2060 de 24 de junio de 2004, por el cual se establecen normas mínimas para Vivienda de Interés Social Urbana.

Ministerio de ambiente, vivienda y desarrollo territorial, Decreto 2181 de junio 29 de 2005, por el cual se reglamentan parcialmente las disposiciones relativas a planes parciales contenidas en la Ley 388 de 1997 y se dictan otras disposiciones en materia urbanística.

República de Colombia, Congreso de la República. Ley 1151 de julio 24 de 2007, por la cual se expide el Plan nacional de desarrollo 2006-2010. 